Marquette University

e-Publications@Marquette

Communication Faculty Research and Publications

Communication, College of

$1-1-2016$

Defining a Medium: The Educational Aspirations for Early Radio

Amanda R. Keeler

Marquette University, amanda.keeler@marquette.edu

Accepted version. Journal of Radio \& Audio Media, Vol. 23, No. 2 (2016): 278-287. DOI. (C) 2016

Taylor \& Francis (Routledge). Used with permission. 


\title{
Defining a Medium: The Educational Aspirations for Early Radio
}

\author{
Amanda Keeler
}

\begin{abstract}
This essay examines the attempts by many writers to steer the burgeoning U.S. radio industry towards educational uses and programming in the 1920s. At the same time that the commercial radio began to take shape, several competing and seemingly incompatible visions of the airwaves emerged - one of which privileged the use of radio for educational purposes. Using discourse from trade journals, general interest magazines, and newspapers, this paper explores the calls for educational programming amid the rapidly expanding and consolidating commercial radio industry.
\end{abstract}

Keywords: Radio, Education, Programming, Noncommercial

In the low-budget horror film Murder by Television (Clifford Sanforth, 1935), Dr. Henry

M. Scofield (Huntley Gordon) discusses new inventions and their uses with Jim Houghland (Charles Hill Mailes). Houghland tells Scofield that "we may invent things, but when you fellows get hold of them, you use them for an entirely different purpose.” As suggested by this exchange, new technologies spark a variety of discussions of future and/or experimental uses. Invariably, the conversation turns to the application of new technology for educational purposes. Like magic lanterns and moving pictures before it, radio in the 1920s prompted enthusiastic commentary in trade journals, magazines, and newspapers regarding its possible educational uses. Writers imbued radio with infinite educational potential as they detailed its seemingly limitless reach into the classroom and the living room. Yet, alongside articles supporting the educational uses of radio were others attesting that the medium's true mission was not to teach, but to entertain.

This essay examines the early discourse that focused on the educational possibilities of radio amid the rapidly emerging commercial radio industry. At the same time that U.S. radio companies and commercial radio began to take shape, several competing and seemingly incompatible visions of the airwaves emerged. Scholars such as Robert McChesney (1993), 
Susan Smulyan (1994), Thomas Streeter (1996), Michele Hilmes (1997), and Hugh Richard Slotten (2009) have detailed how the growth and consolidation of the commercial radio industry, and the implementation of federal regulations, disrupted the viability of widespread educational and/or noncommercial stations and programming. This essay does not repeat the important work of these scholars. Rather, alongside these vital historical accounts, it seeks to demonstrate the early and widespread enthusiasm both for and against the calls for the educational use of radio in the 1920 s.

This essay provides a window into the 1920s when, as Susan Douglas (1987) writes, the “educational possibilities” of radio "seemed unlimited” (p. 309). As Hugh Richard Slotten (2009) notes, "the enthusiasm for radio led many commentators to predict a utopian future for the new public technology. They believed radio broadcasting would raise the cultural standards of the nation and help forge new social and political bonds” (p. 1). William Bianchi (2008) claims that people had "utopian visions" for the future of radio, particularly "for public service, education, cultural uplift, and the unification of contentious populations” (p. 8). A close look at the discourse reveals the nascent years of commercial and noncommercial broadcasting in the United States and the attempts by many writers to steer the burgeoning industry towards educational uses and programming. The debates over education by radio emerged in a number of places—radio trade journals, professional education journals, general interest magazines, and newspapers. The early radio trade journals including Radio Broadcast (1923-1930), and education journals such as School Review, Journal of the National Education Association, and School \& Society, hosted a thriving dialogue on the theoretical promise of educational radio and different experiments underway in schools. These articles also highlighted the difficulties and 
issues that education by radio presented, particularly the concerns over access, costs, and the availability of necessary equipment.

The broad understanding among many was that radio’s true power would be realized by harnessing its educational potential, as evidenced in articles that likened the technology to existing cultural institutions as a way to demonstrate the medium's educational possibilities. For example, the educational journal School Life (1924) suggested that radio promised to follow behind "the school, the library, and the newspaper" as one of the "great educational agencies" (“Educational value of the radio,” p. 178). Dr. James G. Boykins (1925) declared radio the "fourth great agency for education, supplementing the work of schools, libraries and the press" (in Wienand, p. 483). Waldemar Kaempffert (1924), science writer and future director of Chicago’s Museum of Science and Industry saw radio’s future as a “university educating the world” (p. 768). Martin Rice (1924), Director of Broadcasting of the General Electric Company in New York, suggested that radio would "become a great free common school in the not distant future" whose strengths would be in "the enlightenment, the personal culture, and the fullness of knowledge” (p. 83). These accounts reasoned that radio’s future should be educational because of its potential to benefit the lives of listeners everywhere.

In planning for radio's future, Radio Broadcast posed a number of important questions that spoke to the central inquiry about where and how radio would be used. The trade journal asked its readers in 1923: "Will radio serve as an adjunct to ordinary methods of college instruction? Will the instruction given in the classroom be supplemented to an appreciable degree by broadcasted lectures?...Is there a real demand from the radio public for educational lectures of the kind given in college classrooms?” (“A big demand for educational radio?” pp. 94-95). These discussions explored detailed ideas beyond where the education would occur, what 
it would entail, and the possibility of different types of education by radio. For example, John Wallace (1926) explained in Radio Broadcast that educational radio programs could be labeled in three different ways: programs for "secondary schools," "extension courses," and "miscellaneous and occasional lectures broadcast by any old station for whoever cares to listen" (p. 490). These three broad programming types acknowledged that the promotion of education by radio would not be a one-size-fits-all model. Programs would have to be directed at specific grades, populations, or students to target their group educational needs. Alongside the divisions between courses for younger or older students was another partition between two different programming categories: “direct” education, pertaining to a specific subject, lesson for school, or university extension course for college credit, and "indirect" education designed to improve general knowledge and "uplift" the listener through exposure to high-culture arts (Richardson \& Johanningmeier, 2006; Bianchi, 2008; Slotten, 2009; Goodman, 2011). This categorization would come to define how education by radio would be utilized and how it would target different populations.

\section{Education by Radio: From the Classroom to the Living Room}

As evinced by the writers noted thus far, one factor under consideration was where education by radio would occur. For some, radio had the potential to offer superior educational benefits to children in the classroom. Joseph K. Hart (1922) argued that radio would serve as "a single inspiring teacher who speaks to the thousands of revived students through a central radiophone. A whole nation of students might thus come under the stimulating touch of some great teacher” (p. 949). One model put forth involved crafting direct educational radio programs that could act as a sort of "master teacher.” Instead of having one expert speaker travel individually 
to hundreds of schools, radio could facilitate the simultaneous delivery of expert knowledge to thousands or millions of students. This idea stemmed from the notion that a teacher in a rural school might not have the same resources as one in an urban setting. Virgil E. Dickson (1924), Deputy Superintendent of Oakland, California Schools, noted that "schools in remote or inaccessible districts in the country may come in touch with the best supervision and methods of instruction" through a master teacher on the radio (p. 281). This asset would allow a radio program to give students a more specialized lesson than their regular teacher could provide, such as having a scientist teach a lesson in his/her expertise. Grace C. Stanley (1926), Dean of Women at Humboldt State Teacher's College, noted that the possibilities for using radio as a master teacher were "almost unlimited" (p. 156). She claimed that, "by the use of radio the work of a great teacher can be immeasurably extended" (Stanley, 1926, p. 156). The master teacher promised to bring educational material far and wide via radio, conceivably leveling the quality and availability of educational opportunities across school districts. Further, Virgil E. Dickson (1924) saw merit in teachers learning from experts via radio. He reasoned that "almost any teacher can and will be inspired to better work and better methods by observation of the development of a lesson taught by an expert in the subject” (Dickson, 1924, p. 281). In this way the master teacher would benefit both the student and the teacher; the student learns from someone at the top of an educational field and the teacher in turn learns more about these subjects to pass along to students.

The idea of the master teacher enticed others because it invoked the notion that radio could prove to be more "efficient" than other pedagogical methods. School Review (1923) saw this efficiency in radio's ability to relay "educational information...promptly, cheaply, widely" (“Broadcasting educational material,” p. 248). John Tigert (1923) noted radio’s efficiency was 
two-fold in that it was “cheaper than printing” and that it reached "its audience quicker” (in Bawden, p. 231). Working with the Payne Fund, Armstrong Perry (1929) claimed that "the expense of teaching pupils in the public schools by means of radio is much less than the cost of instruction by any other known means” (p. 38). The idea of efficiency also filtered into discussions concerning which educational subjects might be best facilitated through radio. For example, Radio Broadcast reported in 1922 that radio was well suited for "the dissemination of information regarding health” (“Broadcasting health,” p. 7). Radio education supporters listed a vast array of subjects that they felt were amenable for delivery via radio to students in the classroom. Martin Rice (1924) observed that "lecture courses can be planned in the fine arts, biology, literature, and the physical sciences” (p. 82). Importantly, the efficiency of the master teacher, as envisioned in this way, did not diminish the quality of information presented, but rather promised a way to deliver the same learning to classrooms everywhere. These comments demonstrate a vast enthusiasm for the potential of the medium of radio to benefit classrooms, teachers, and students in a variety of positive ways, and across a wide range of disciplines.

The promotion of education by radio was not only for schoolchildren in classrooms. Another side of the discussions about radio for education took into account how radio could be used to educate people in their homes, where it had the potential to reach vast numbers of adults and homebound children. Throughout the discourse many writers envisioned radio reaching and educating people who were geographically out of reach of traditional learning institutions. Higher education institutions had an early interest in broadcasting extension courses, in which a radio station “operated directly in conjunction with an educational institution” (Shurick, 1946, p. 293). Extension courses were considered “direct” education in that participants earned college credit by listening to the programs and completing the required homework and tests (Bianchi 
2008; Slotten, 2009). Extension courses promised to bring education to distant regions underserved by traditional schools and populations who "would not otherwise be reached," such as rural farmers who were located too far from cities or universities to attend school (“Broadcasting educational material,” 1923, p. 249). School Life (1924) suggested that radio offered the "greatest boon" because it brought education to "farmers and to dwellers in isolated regions” (“Educational value of the radio,” p. 178). Martin Rice (1924) reasoned that one prospect along these lines would be the "establishment of 'radio night schools.' Many young men and women (and older folks as well), who are not within reach of public evening classes or who are prevented by any of a hundred causes from leaving home, will welcome an opportunity for study that is brought to their very rooms” (p. 82). Virgil E. Dickson (1924) quoted a mother who looked forward to receiving educational radio in her home, noting that she "cannot get to the school building” but wanted radio to help her understand her children's education (p. 280).

Unlike the extension courses meant to provide high school or college credit, most of the proposed uses of radio in schools and at home were considered "indirect" education. This type of educational programming instead added to a listener’s general knowledge about a subject (“A big demand for educational radio?” 1923, p. 95). For example, music appreciation courses fell into the indirect education category. Radio Broadcast (1923) reported that the demand for this type of informal education by radio existed, particularly for the type one could receive from "listening to good musical numbers or opera," which the magazine felt was akin to "receiving education and inspiration” (“A big demand for educational radio?” p. 95). School Review (1923) felt that illiterate adult listeners were an important group that could be taught to read with radio, particularly if they were too embarrassed to do so in a classroom outside of the home (“Broadcasting educational material,” p. 248). Indirect educational programming could also be 
used to provide the "timely personal advice such as a good family physician gives" without the expense of a doctor’s visit (“Broadcasting health,” 1922, p. 7). Kansas City mayor Frank H. Cromwell (1923) also saw merit in the use of radio for civics lessons for voters (in Simpson, p. 302).

The rhetoric above promoted the idea of radio for educational purposes, and identified some of the different ways radio was perceived to be an asset in the classroom and the living room. These articles suggested vibrant ways that radio might be utilized in these disparate spaces. Nonetheless, it was not as simple as merely deciding to use radio for educational purposes. There were unresolved matters of who would create and air the necessary programs, as well as issues with access, costs, and the availability of necessary equipment.

\section{Objections and Concerns}

While the statements above make evident the enthusiasm surrounding the use of radio for educational purposes, another series of articles instead featured writers who expressed their criticism towards radio education. For example, in 1926 John Wallace penned an article for Radio Broadcast titled "Sad news: Why radio cannot educate," in which he pointed to the tendency to privilege new technology as a means of improving or superseding existing educational methods. He claimed that "radio lectures constitute a sort of glorified correspondence course” and were not necessarily an improvement over existing methods (Wallace, 1926, p. 490). Wallace further suggested that the proponents of radio education "have a personal interest in the matter” and were “inclined to overestimate radio’s teaching ability enormously” (1926, p. 490). Several years later he reiterated these thoughts, again noting that in the rush to bring this new technology to the classroom, teachers were guilty of using radio to 
teach subjects unsuitable for auditory learning, such as geography, which he felt was an “obviously silly” subject for radio and far more suited for visual learning (Wallace, 1928, p. 166). Wallace used hyperbolic language across these two articles to convince his readers that the rhetoric promoting education by radio was not taking into account a number of clear and present obstacles.

With a similar sentiment, Bruce Bliven (1924) also disagreed with claims that radio was somehow going to correct any manner of educational woes. Bliven made clear in Century Magazine his opinion that radio's true purpose was not for education. In his article, "How radio is remaking our world," Bliven remarked that "the primary function of radio” was “entertainment” (1924, p. 150). As such, he felt that "radio is not likely, on the basis of any inventions now perfected or in sight, to become an important factor in the education of the young” (Bliven, 1924, p. 152). Further, Bliven questioned whether adults wanted their radio programs to teach them. He felt that the majority of people did not mind "getting some facts" from the radio, but he saw "no signs that more than a highly insignificant minority of adults want to acquire a comprehensive knowledge of anything whatever" (Bliven, 1924, p.152). He remained firm that radio needed to be entertaining and that since radio had the ability to reach and unite many people at once, it seemed foolhardy to offer educational programming that would only appeal to an "insignificant minority" (Bliven, 1924, p. 152). Regardless of whom it targeted or would benefit, Bliven felt that educational programming would never draw audiences in the same way as entertainment programs. On Bliven’s final comment the journal School Life agreed. Though generally supportive of educational radio in other articles, School Life noted in 1924 that "the educational effect of the radio is comparable to that of the newspaper. Those who listen in 
do so as a rule for the entertainment they get out of it, and not because they wish or expect to be educated that way” (“Educational value of the radio,” p. 178).

Other writers wanted readers to understand that teachers would have a difficult time bringing radio in the classroom successfully because of time constraints. If using radio in the classroom meant that a teacher had to put in more work to achieve the same level of student learning, then this brought its overall effectiveness into question. The issue with time was a real concern, particularly if one of the selling points of education by radio was its efficiency.

Teachers also had to contend with the inflexible access to relevant programs. Programming aired at specific times of the day-not necessarily in conjunction with the school day or during a convenient listening time for teachers and students. Despite the free programming that flowed into radios, there was no guarantee that a particular subject might be covered during the time when students were in a particular class, or at the time of year that a lesson was under examination in the classroom. Furthermore, there was no guarantee that each classroom would be equipped with radios to air these programs for their students.

At the center of these objections to education by radio was the idea that the technology was not capable of providing a comparable service to what teachers had been doing for centuries in the classroom. Virgil E. Dickson allayed fears that radio would fundamentally change the classroom for the worse. He noted that there was "no reason to believe that radio lessons will in any sense affect the number of classroom teachers needed or the general nature of classroom organization” (Dickson, 1924, p. 281). According to Radio Broadcast in 1923, the radio itself was no substitute for a teacher presenting the material to students in person. The journal published an article explaining that "the gesture and the personality of the instructor, and the blackboard illustration, as well as the student's interest in the subject matter, serve to hold his 
attention. But no such advantages rest with the radio lecturer” (“A big demand for educational radio?” p. 95). Contrary to the positive words about radio's ability to deliver master teachers noted above, some suspicion remained, stemming from fears that the audio instruction would come to replace the living, breathing teacher in the classroom. Despite these fears, there was little evidence to suggest that radio could replace teachers entirely.

As noted earlier, some privileged the idea that a master teacher could "efficiently" teach thousands of students at the same time. Though theoretically able to reach students in classrooms everywhere, the master teacher was another ambitious idea that would have to be experimented with to discover how it might and might not work. Connected to these remarks about the master teacher, Arthur E. Morgan (1924), Antioch College president, felt that radio in general was not a proper way to teach. He remarked that his college was "planning no courses of study for broadcasting" and that he did "not believe it is at present possible to obtain an education in that way" ("Limits of education by radio," 1924, p. 81). Morgan did not mean that certain types of subjects were impossible to teach via radio, but rather that in his opinion education was "not merely accumulated knowledge” ("Limits of education by radio,” 1924, p. 81). The processes by which people learned in the classroom were more intricate than merely absorbing information. They involved interaction between students and the teacher, demonstrations, and laboratory exploration—none of which Morgan thought possible through radio.

The expense of new technology was another key concern in the discourse regarding the feasibility of using radios in school and in the home. The implementation of new technology in the classroom brought worries that the equipment would be cost-prohibitive, particularly the purchase of equipment to receive radio signals, and microphones. In 1921-23, for example, the Westinghouse/RCA Aeriola Senior sold for \$65.00 [\$865 in 2016 dollars] (Western Historic 
Radio Museum website). ${ }^{1}$ Radio prices dropped quickly throughout the 1920s, and by 1928 a Crosley radio cost \$25 [\$348 in 2016 dollars] (Crosley Radio Sales Brochure, 1928). The price of one radio set did not include maintenance and repair costs. Because radios could only project sound so far, schools sometimes needed to purchase multiple sets. Rooms needed electricity and not all schools were wired for this. Bruce Bliven commented that "not only is broadcasting apparatus expensive to install, but it becomes increasingly expensive to maintain” (1924, p. 151).

Aside from the expense of the sets in the classroom, one large cost issue remained: programming. Who would create these programs, and how would they be funded? Weather reports, lectures, music performances, extension courses—each of these had to be financed somehow. Weather reports, for example, needed a person to relay the information from the science labs on campus to the radio station. Lectures, on the other hand, were often free if they involved professors at the university, but an expert in town who gave a guest lecture might have expected a financial consideration. Musical performances required the station to pay royalties to record companies and publishers (Rinks, 2002). Extension courses received tuition that was used to subsidize the instructors' pay but may still have needed additional funds. In addition to the onair talent, a number of behind-the-scenes people were necessary to keep a station on the air. Someone had to keep the electrical equipment in working order. The station manager had to insure that the station kept its license current and to arrange a full schedule of programming. As School \& Society noted, "unless special rates are made for educational programs they cannot be made self-supporting” (“Education by radio,” 1929, p. 749). This would prove to be a correct premonition.

\section{Conclusion}


Radio promised to bring modern technology into the classroom as an update to the textbook and the blackboard. It invoked positive ways to utilize new technology to help students learn better, more effectively and efficiently, and to make the teacher's work easier. Radio education proponents claimed that radio would level the educational field in the United States, bringing expert knowledge to classrooms everywhere, regardless of the location or socioeconomic status of a school. Opponents of education by radio saw the apparatus as a threat to the relationship between student and teacher, and claimed that this new medium was better suited for entertaining programs that attracted mass audiences.

For all of the positive discourse proclaiming that radio would forever transform the classroom, the educational success of radio as envisioned by its supporters was never realized. dEducational programming via radio never reached the level of usage or excitement predicted in its earliest days. A number of factors contributed to this decline, including general disinterest from the listening public, as predicted by writers such as Bruce Bliven (1924), as well as the treatment by federal regulators whose legislation and licensing favored commercial radio (McChesney, 1993; Smulyan, 1994; Streeter, 1996; Hilmes, 1997; Slotten, 2009). Education by radio peaked among university stations in the 1920s, and though it found some success on commercial radio in the 1930s, it failed to meet the hyperbolic promises attributed to it (Rinks, 2002; Bianchi, 2008; Slotten, 2009). The New Republic reported this sentiment in 1930, noting that

From the beginning of radio, ten years ago, high hopes have been held out for its use in education. We were told then, as we are told now, that this marvelous device will prove a mighty tool in teaching old and young. Yet in ten years' time so little progress has been made that it is scarcely visible to the naked eye. Most of the attempts which have been made in the meantime to use the radio in education, in the United States, have failed for one reason or another and have been abandoned. (357) 
Educational radio programming did not end because Variety and other magazines declared it a dead prospect. It continued in some form, at least until television emerged as the next great educational technology that promised to forever change education, both in the classroom and in the home (Cuban, 1986).

This essay examined the discourse across the 1920s that both lauded and criticized the proposed educational uses of radio for educational purposes. The articles and writers discussed above represent a sampling of the rhetoric that circulated around radio and education, though together they situate the discourse around educational radio as nuanced, complex, and worthy of continued analysis.

${ }^{1}$ All 2016 dollar amounts are calculated using the U.S. Department of Labor-Bureau of Labor Statistics Consumer Price Index Inflation Calculator. http://data.bls.gov/cgi-bin/cpicalc.pl

\section{References}

A big demand for educational radio? (1923, June) Radio Broadcast, 3, 94-97.

Bawden, W. T. (1923, February). Radio program of the bureau of education. Industrial Education Magazine, 24(8), 231.

Bianchi, W. (2008). Schools of the air: A history of instructional programs on radio in the United States. Jefferson: McFarland and Company, Inc. Press.

Bliven, B. (1924, June). How radio is remaking our world. The Century Magazine, 108(2), 147-54.

Broadcasting educational material. (1923, April). School Review, 31(4), 247-49.

Broadcasting health. (1922, November). Radio Broadcast, 2, 7-8. 
Crossley radio sales brochure. (1928-29). Retrieved from http://www.crosleyradios.com/pdf/1928-1929_Box_Brochure.pdf

Cuban, L. (1986). Teachers and machines: The classroom use of technology since 1920. New York: Teachers College Press.

Dickson, V. E. (1924, November). Radio in Oakland schools. Journal of the National Education Association, 13(9), 279-82.

Douglas, S. J. (1987). Inventing American broadcasting, 1899-1922. Baltimore: The Johns Hopkins University Press.

Education by radio. (1929, June 8). School \& Society, 29(754), 749.

Educational value of the radio. (1924, April). School Life, 9(8), 178.

Goodman, D. (2011). Radio's civic ambition: American broadcasting and democracy in the 1930s. Oxford: Oxford University Press.

Hart, J. K. (1922, March 18). Radiating culture. Survey, 47(25), 948-49.

Hilmes, M. (1997) Radio voices: American broadcasting, 1922-1952. Minneapolis: University of Minnesota Press.

Kaempffert, W. (1924, June). The social destiny of radio. Forum, 71(6), 764.

Limits of education by radio. (1924, April 19). The Literary Digest, 81(3), 81-82.

Murder by television. (1935). Directed by Clifford Sanforth.

McChesney R.W. (1993). Telecommunications, mass media, and democracy: The battle for the control of U.S. broadcasting, 1928-1935. New York: Oxford University Press.

Perry, A. (1929). Radio in education: The Ohio school of the air and other experiments. ( $2^{\text {nd }}$ ed.). New York: The Payne Fund.

Radio and education. (1930, August 13). New Republic, 63(819), 357-58. 
Rice, M. P. (1924, March). The future of radio education. Journal of the National Education Association, 13(3), 82-83.

Richardson, T. R. and Johanningmeier, E. V. (2006). Educational radio, childhood, and philanthropy: A new role for the humanities in popular culture, 1924-1941. Journal of Radio Studies, 13(1), 1-18.

Rinks, J. W. (2002). Higher education in radio, 1922-1934. Journal of Radio Studies, 9(2), 303-16.

Shurick, E. P. J. (1946). The first quarter-century of American broadcasting. Kansas City: Midland Publishing Company.

Simpson, J. L. (1923, August). Selling the public on better city government. Radio Broadcast, 3, 299-302.

Slotten, H. R. (2009). Radio's hidden voice: The origins of public broadcasting in the United States. Urbana: University of Illinois Press.

Smulyan, S. (1994). Selling radio: The commercialization of American broadcasting, 19201934. Washington, D.C.: Smithsonian Institution Press.

Stanley, G. C. (1926, May). Radio in California schools. Journal of National Education Association, 15(5), 156.

Streeter, T. (1996). Selling the air: A critique of the policy of commercial broadcasting in the United States. Chicago: University of Chicago Press.

Wienand, C. M. (1925, April). Radio in education. Communicated by F. E. Bolton. Education, 45(8), 483-88.

Wallace, J. (1926, October). Sad news: Why radio cannot educate. Radio Broadcast, 9, 490-91. 
Wallace, J. (1928, July). A fine program you will never hear. Radio Broadcast, 13, 165-66.

Western historic radio museum website. Retrieved from

http://www.radioblvd.com/20sRadio.html 